\title{
Desapariciones en México: la emergencia de un campo \\ ₹
}

\section{Disappearances in Mexico: the Emergence of a Field}

\author{
Camilo Vicente Ovalle \\ Investigador independiente \\ México \\ Correo: camilovcontacto@gmail.com \\ ORCID: https://orcid.org/0000-0003-4120-9532 \\ DOI: 10.48I02/hyg.vi56.353
}

Artículo recibido: o I/07/2020

Artículo aceptado: 24/08/2020

\section{ABSTRACT}

Recently a social, academical and political field, has been configurated around the enforced disappearances in Mexico. This complex field articulates victims and humans' rights organizations, scholars and journalist, as well as governmental institutions, is been explained by a hypothesis that considers the transnationalization of the category "original detainee-disappeared". Neither the hypothesis nor the emergence of the field corresponds to the historical development of the disappearance in Mexico. Considered these factors, and also the long history of the enforced disappearances in Mexico, this article proposes an analysis of the conditions that didn't allow the configuration of a field around the enforced disappearances in the aftermath of counterinsurgency. Two factors are presented for discussion: a theoretical perspective on authoritarianism and repression of the Mexican State, and differences and conflicts in the spectrum of the Mexican left-wing.

Key words: Enforced Disappearances, Political Violence, Counterinsurgency, Human Rights, Mexico. 


\section{Resumen}

De manera reciente se ha configurado un campo social, académico y político en torno a la desaparición de personas en México que le ha dado realidad social al fenómeno. La configuración del campo, que articula organizaciones de víctimas, de derechos humanos, académicas y periodistas, e instituciones gubernamentales, se ha intentado explicar a través de la hipótesis de la transnacionalización de la categoría "detenido-desaparecido originario". Sin embargo, ni la hipótesis ni la emergencia del campo se corresponden con el desarrollo histórico de la desaparición en México. Considerando estos elementos, particularmente la existencia de larga data de la desaparición forzada en México, se propone una reflexión sobre la ausencia previa de una configuración de un campo social de la desaparición. Se presentan a la discusión dos factores: una perspectiva teórica sobre el autoritarismo y la represión en el Estado mexicano, y las diferencias y conflictos en el espectro de las izquierdas mexicanas.

Palabras clave: desaparición forzada, violencia política, contrainsurgencia, derechos humanos, México.

\section{INTRODUCCIÓN}

$\mathrm{H}_{\mathrm{s}}$

oy reconocemos, en la desaparición de personas, una de las formas de la representación de nuestra catástrofe social: 60 mil personas desaparecidas entre los años 2006 y 2019, de acuerdo con los registros oficiales, ${ }^{1}$ y miles de familias que viven el drama de la desestructuración que acompaña la desaparición de una persona. La magnitud de este fenómeno en la última década ha develado la crisis de derechos humanos ${ }^{2}$ y las formas de una nueva gubernamentalidad gestada en la violencia, ${ }^{3}$ expresada en voz de los cientos de familiares que recorren el país buscando y exhumando.

${ }^{1}$ Comisión Nacional de Búsqueda, "Informe sobre fosas clandestinas y registro nacional de personas desaparecidas o no localizadas".

${ }^{2}$ Alejandro Anaya-Muñoz y Bárbara Frey (eds.), Mexico’s Human Rights Crisis.

${ }^{3}$ Pilar Calveiro, Resistir al neoliberalismo: comunidades y autonomías.

\section{4 / Camilo Vicente Ovalle}


Tal reconocimiento no sólo se ha debido a la magnitud de la catástrofe ni mucho menos a que se haya prestado oportuna atención al grito “¿Dónde están?”, de las madres y familiares de víctimas de desaparición. El reconocimiento de la catástrofe es el producto, en parte fundamental, de la configuración, desde la emergencia, de un campo social de la desaparición: que articula a organizaciones de víctimas, instituciones gubernamentales, académicos y especialistas, y organismos internacionales de derechos humanos que administran la circulación de conocimiento, gestionan los reclamos, otorgan validez a los actores del campo y fuera de él. ${ }^{4}$ En sus acciones y disputas dicho campo ha dotado de una realidad social a un fenómeno que, aunque con una presencia muy anterior en nuestro país, no lo había tenido.

Esto último constituye la pregunta que guía el desarrollo de este texto. La configuración del campo, tal como ha emergido de manera muy reciente, no se corresponde con la existencia y desarrollo histórico del fenómeno de la desaparición en México, cuestión que evidencia, entonces, que la emergencia de un campo social no está sólo ni necesariamente vinculado con la gravedad o magnitud de un fenómeno. Para el caso mexicano resulta fundamental, entonces, antes que abordar el campo mismo, preguntarse por las condiciones o factores que no habían permitido la emergencia de un campo social de las desapariciones.

Contrario a otras experiencias y a pesar de que la desaparición forzada tiene larga data en México, no había emergido ningún campo social en torno a ella. Sin embargo, en años recientes, quizá no más allá de una década, hemos presenciado la emergencia del campo de las desapariciones cuyo desarrollo ha implicado no nada más la construcción de figuras potentes como la de víc-

\footnotetext{
${ }^{4}$ Un campo está determinado por las posiciones y relaciones entre los actores que lo componen y las disputas en torno a un capital que le es común; con un sentido topológico permite describir "un estado de las posiciones sociales", los agentes y las fuerzas que se encuentran en él, véase Pierre Bourdieu, Razones prácticas: sobre la teoría de la acción.
} 
tima, sino la creación de instituciones estatales especializadas en desapariciones y víctimas, y un campo de estudios que se ha ido fortaleciendo rápidamente en torno al fenómeno actual. En este proceso, llama la atención que este campo de las desapariciones no necesitó, ni consideró, la existencia previa de desapariciones forzadas cometidas en el periodo de contrainsurgencia entre las décadas de 1960-1980. En apariencia, su referente y condición de posibilidad fue la magnitud que el nuevo tipo de desapariciones, con toda claridad a partir de 2006, alcanzaron en nuestro país, hasta convertirlas en el significante de nuestra catástrofe presente.

Para explicar esto, una hipótesis ha ido ganando fuerza: aquella que considera que este campo se articuló a partir de una categoría de "detenido-desparecido", gestada en la Argentina de la dictadura, que fue transnacionalizada $y$, dada su potencia apoyada en la red internacional de organismos de derechos humanos, organizó el campo de la desaparición.

En este texto me interesa identificar y poner a discusión, a partir del desarrollo histórico de la desaparición en México y de los supuestos de la hipótesis de la transnacionalización, algunos elementos que permitan construir una explicación en torno a por qué no se configuró un campo en torno a la desaparición forzada, incluso cuando, desde mediados de la década de 1970, comenzaron a constituirse agrupaciones de madres y familiares, y cómo el campo de la desaparición que se teje en torno a un nuevo tipo de desapariciones tiende a desplazar las experiencias anteriores.

\section{LA HIPÓTESIS Y EL CAMPO}

En los últimos años un campo social de la desaparición en México fue conformándose, principalmente, por las propias organizaciones de familiares de víctimas, organizaciones de derechos humanos nacionales e internacionales, instituciones gubernamentales especializadas en las víctimas y la desaparición, departamentos o 
grupos de investigación dentro de instituciones académicas, y grupos de periodistas. En este campo se articulan no sólo los diversos actores, también saberes expertos, repertorios de acción y lenguaje que le dan consistencia y presencia en el ámbito público.

Como lo han señalado algunos autores, este campo es más o menos reciente, ${ }^{5}$ quizá data de poco más de una década. Aún no se ha analizado con suficiente profundidad la conformación del campo de la desaparición en México, en particular la forma en que el campo ha configurado a los actores que en él se encuentran, y cómo la disputa ha formado y transformado el rostro de las víctimas y sus reclamos.

Prima facie, pareciera que la configuración del campo encuentra su posibilidad por la magnitud de la catástrofe a partir de mediados de la década del 2000. Pero el sentido de la catástrofe no es posible determinarlo a partir de sus consecuencias, como el costo humanitario y la masividad que ha alcanzado, porque antes de llegar a la masividad ya anunciaba una catástrofe, ${ }^{6}$ como lo podemos comprender a partir de las desapariciones de la contrainsurgencia, entre los años de 1960 y 1980. Si bien de un orden distinto a las desapariciones actuales, la desaparición como recurso represivo tiene larga data en México; se le conoció muy pronto, en el proceso mismo de consolidación autoritaria del Estado. Existe evidencia de su práctica, por parte del Ejército y corporaciones policiacas, principalmente la Dirección Federal de Seguridad (DFS), desde la década de 1940. ${ }^{7}$ Esta presencia temprana de la práctica dentro del Ejército y las policías facilitó la implantación de formas más sofisticadas que llevaron a la con-

\footnotetext{
${ }^{5}$ Gabriel Gatti e Ignacio Irazuzta, "Diario de la desaparición mexicana. Entre el precedente y el exceso"; y Carolina Robledo Silvestre y May-ek Querales-Mendoza, "Presentación del dossier. Desaparición de personas en el mundo globalizado: desafíos desde América Latina”.

${ }^{6}$ Sobre el sentido de catástrofe en las desapariciones véase Gabriel Gatti, El detenido-desaparecido: narrativas posibles para una catástrofe de la identidad.

${ }^{7}$ Camilo Vicente Ovalle, [Tiempo Suspendido] Una historia de la desaparición forzada en México, 1940-1980.
} 
figuración como se presentó durante la contrainsurgencia, hasta convertirse en una técnica para la eliminación, lo que implicó grados más altos de coordinación entre el Ejército y las policías. Sin embargo, esta catástrofe anunciada no produjo la configuración de un campo.

Hace poco tiempo, una hipótesis ha encontrado suficiente aceptación para convertirse en explanans de la configuración del campo de la desaparición en México. Es la hipótesis de la invención social de la categoría del detenido-desaparecido en la Argentina de la dictadura de 1976-1983: el "desaparecido originario”. Elaborada por el sociólogo uruguayo Gabriel Gatti, sostiene que la categoría del "desaparecido originario" se transnacionaliza, y coloniza espacios geográficos, históricos y epistémicos, hasta convertirse en tipo ideal: el desaparecido permanente a manos del Estado, que caracteriza a la desaparición forzada, y que se ha asentado, alrededor de América Latina y el mundo, a través de los distintos usos locales y su naturalización en espacios y temporalidades extraños al origen de la categoría y su composición originaria. ${ }^{8}$ La transnacionalización consiste, particularmente, en su inscripción jurídico-normativa en la amplia red de organismos internacionales, convenciones o cortes, en donde el detenido-desaparecido y la desaparición forzada se fijan como tipo ideal y se convierten en la medida de todas las formas de desaparición. De acuerdo con Gatti, su ruta fue la siguiente:

El detenido-desaparecido ya circula planetariamente: nació en los centros clandestinos de detención argentinos, de los que surgió el desaparecido originario. Sufrió luego dos transformaciones: en un primer movimiento, sin perder complejidad, pero sí matices, devino mediante intenso trabajo de traducción jurídica desaparecido transnacional; luego, en un segundo movi-

${ }^{8}$ Gabriel Gatti, "De un continente al otro: el desaparecido transnacional, la cultura humanitaria y las víctimas totales en tiempos de guerra global”; Gabriel Gatti, "Prolegómenos. Para un concepto científico de desaparición”. 
miento se convirtió en la matriz con la que se piensan y se miden, y si se puede, se juzgan múltiples casos de desaparecidos locales ya integrados en el tipo transnacional. ${ }^{?}$

La configuración del campo de la desaparición en México, siguiendo esta hipótesis, estuvo determinada en lo fundamental por la transnacionalización y naturalización muy reciente de la categoría del "detenido-desaparecido". Para Gatti, esta transnacionalización se ha aplicado en casos como México bajo las "guerras contra el narcotráfico", "para cuyas víctimas no existía nombre hasta que el de detenido-desaparecido se aplicó". ${ }^{10}$ En un artículo reciente, Gatti e Irazuzta señalan:

El texto está organizado por lo que entendemos son los grandes rasgos del campo mexicano de la desaparición: que deriva de un precedente de una "desaparición originaria" que se ve excedida [...] En México, aunque ya parece que se lleva desde siempre hablando de ello, la desaparición llegó hace poco pues pocos han sido los hechos que han sido nombrados como desaparición. No es raro: los aterrizajes en contextos locales de las categorías presuntamente universales que componen el complejo paquete de los derechos humanos suelen ser silenciosos, pero cuando están, parece que están allí desde siempre. ${ }^{11}$

Y aunque la hipótesis misma plantea cuestionamientos a la forma en que se han dado los usos de la categoría del "detenido-des-

${ }^{9}$ Gatti, "Prolegómenos", op. cit., p. 22. Sobre la tensión que se produce para ampliar el concepto de desaparición forzada a casos en los que no participa el Estado, véase el interesante artículo de Pietro Sferrazza-Taibi sobre los estándares de atribución de la Corte Interamericana de Derechos Humanos para declarar la responsabilidad del Estado en casos de desapariciones forzadas cometidas por actores no estatales. Pietro Sferrazza-Taibi, "Desapariciones forzadas por actores no estatales: la jurisprudencia de la Corte Interamericana de Derechos Humanos".

${ }^{10}$ Gatti, "Prolegómenos", op. cit., p. 23.

${ }^{11}$ Gatti e Irazuzta, "Diario de la desaparición", op. cit., pp. 4-5. Cursivas mías. 
aparecido originario" desdibujando experiencias de violencias que no le serían propias, no son críticas a la hipótesis, sino su confirmación. ${ }^{12}$

En efecto, el tipo ideal de detenido-desaparecido que produce la desaparición forzada, despliega un poderoso aparato internacional que establece los lindes de significación y acción, en las distintas lógicas de violencia en las que se puede presentar. Sin embargo, la idea de originalidad resulta problemática, no porque genéticamente la categoría tal cual cristalizó en un tipo ideal y no cuente con una cuna, sino porque eso no es suficiente para comprender y explicar el caso mexicano, y menos cuando el supuesto de la hipótesis es la consideración de territorios vacíos de experiencia o cuya experiencia es desplazable con facilidad. Ya Marc Bloch había alertado sobre la obsesión por los orígenes: "para el léxico común, los orígenes son un principio que explica. Peor aún, que basta para explicar. Ahí está la ambigüedad; ahí está el peligro". ${ }^{13} Y$ esto se comprueba en la aceptación de la hipótesis de la transnacionalización y naturalización de la categoría originaria, en la que no hay ni siquiera un esfuerzo por indagar la experiencia anterior al momento de la llegada de la categoría transnacional a un "nuevo" territorio. La hipótesis presenta varios vacíos explicativos para comprender la emergencia y dinámica del campo de la desaparición en México.

En primer lugar, habría que preguntar qué tan exitosa, como lo han señalado, ${ }^{14}$ ha sido la transnacionalización y su naturalización en términos de organización del campo en la última década en México. Porque una vez instalada la catástrofe, la categoría del "detenido-desaparecido originario" parece no tener ninguna capacidad de organizar y, más bien, se presenta como problemá-

${ }^{12}$ Élisabeth Anstett, "Comparación no es razón: a propósito de la exportación de las nociones de desaparición forzada y detenidos-desaparecidos".

${ }^{13}$ Marc Bloch, Apología para la historia o el oficio del historiador, p. 60.

${ }^{14}$ Gatti, "Prolegómenos", op. cit., 23; Gatti e Irazuzta, "Diario de la desaparición”, op. cit., p. 5. 
tica a la reflexión y a la acción, con pobres resultados. Gatti e Irazuzta señalan esta tensión: "Entre las [desapariciones] forzadas y las que no lo son se estructura en gran medida el campo de la desaparición en México", ${ }^{15}$ pero las tensiones no están en lo que integra, sino en lo que excluye. El tipo jurídico establecido como ideal no sólo provoca distorsiones y dificultades para comprender las formas de desaparición actuales, también genera distorsiones en la comprensión de especificidades históricas que no coinciden con él: así como subsume pasados que no la conocieron y desplaza procesos históricos que no coinciden con su uso específico, el tipo ideal es forzado a dar cuenta de presentes que ya no alcanza a aprehender bajo su sombra. ${ }^{16}$

En segundo lugar, la hipótesis sostiene que la transnacionalización de la categoría de "detenido-desaparecido" hacia México se dio de manera muy reciente y se naturaliza sobre un fenómeno que no corresponde a su estructura originaria. Sin embargo, nunca se brinda una explicación sobre la temporalidad, por lo que habría que cuestionarse al respecto. Sin duda alguna la categoría de "detenido-desaparecido" viajó sostenida por las madres y familiares de desaparecidos, principalmente las argentinas pero también uruguayas y chilenas, que entre mediados de los años setenta y ochenta del siglo xx salieron a buscar el respaldo internacional, y luego los organismos de derechos humanos institucionalizaron la categoría e instrumentalizaron las denuncias contra los regímenes autoritarios o dictatoriales, ${ }^{17}$ produciendo una estructura externa de oportunidad que favoreció a los movimientos de madres en casos como el argentino. ${ }^{18}$ Sin embargo, su "arribo" a México no ha

\footnotetext{
${ }^{15}$ Gatti e Irazuzta, "Diario de la desaparición”, op. cit., p. 7.

${ }^{16}$ Carolina Robledo muestra las dificultades del uso del concepto de la desaparición forzada, tal como fue "heredado de la guerra sucia", para comprender los nuevos tipos de desapariciones. Robledo Silvestre, "Genealogía e historia no resuelta de la desaparición forzada en México”, p. 106.

${ }^{17}$ Ibidem, pp. 97-99.

${ }^{18}$ Iosif Kovras, Grassroots Activism and the Evolution of Transitional Justice. The Families of the Disappeared.
} 
sido reciente. Como lo ha señalado el historiador Pablo Yankelevich, desde 1976 el exilio argentino en México desarrolló una intensa actividad en torno a las desapariciones forzadas en Argentina, difundiendo con amplitud los casos en la prensa mexicana e impulsando la creación de colectivos de solidaridad, instalando el uso y la discusión en el ámbito público sobre la desaparición y los detenidos desaparecidos en aquel país. ${ }^{19}$ Sin embargo, esta temprana "exportación" no produjo un campo. Y la razón no fue, como se ha supuesto, porque antes de la transnacionalización pocos o ningún hecho habían sido nombrados como desapariciones.

En este sentido, y en tercer lugar, quizá el cuestionamiento más importante hacia la hipótesis es en relación con su supuesto de que la transnacionalización se da en territorios vacíos o cuya experiencia es desplazable. Esto, además de no ser preciso, muestra poca comprensión histórica del fenómeno de la desaparición en México.

La detención-desaparición forzada como forma de represión política tiene larga data en México, y se le nombraba como "desapariciones" (incluso desde la década de los cuarenta), con toda la significación que adquiriría después en el ámbito internacional. Ya desde principios de los setenta la Asociación Cívica Nacional Revolucionaria (ACNR) constantemente hizo mención, en sus comunicados, de la detención-desaparición de sus militantes. Por ejemplo, el comunicado del 6 de enero de 1971:

Chilpancingo, Iguala, Atoyac, son ciudades mártires; el asesinato de los copreros; la actual represión del ejército contra los pueblos indígenas de la montańa, los asesinatos bestiales por el $48^{\circ}$ Batallón de Infantería en esta misma región; Antonio Espinobarros, Irineo Juárez Castro, entre otros, asi como la desaparición de German Espinobarros.

${ }^{19}$ Pablo Yankelevich, Ráfagas de un exilio: argentinos en México, 1974-1983, pp. 221-253. Para el caso uruguayo véase Silvia Dutrénit, El Uruguay del exilio: gente, circunstancias, escenarios; Silvia Dutrénit y Fernando Serrano Migallón, El exilio uruguayo en México.

62 / Camilo Vicente Ovalle 
O el comunicado de julio de 1971:

Por cierto, median meses ya de la detención de decenas de ciudadanos de la región, sin que ni la Secretaría de la Defensa ni la Procuraduría General hagan el menor indicio de cumplir con los deberes legales inherentes a su cargo informando de las gentes aprehendidas por corporaciones que están bajo sus órdenes. ${ }^{20}$

Puede suponerse que por el cerco comunicativo que la prensa y los medios de comunicación masiva tenían sobre las organizaciones disidentes, en especial las guerrilleras, su reclamo no alcanzó la sensibilidad nacional, por lo que la categoría de "detenido-desaparecido" no haya aparecido en el ámbito público, impidiendo la difusión de una experiencia. Sin embargo, al menos desde mediados de la década de 1970 la prensa, tanto de circulación nacional como regional, comenzó a hacerse eco de las nacientes organizaciones que pugnaban por la libertad de los presos y la presentación de los desaparecidos. Periódicos como el Excélsior, antes del golpe a su director Julio Scherer (1976); o a nivel local, por ejemplo en Sinaloa el Noroeste, en 1976 encabezó una campaña mediática contra las violaciones a los derechos humanos, $\mathrm{y}$ entre 1977 y 1978 fue un espacio abierto para las madres de los detenidos-desaparecidos en esa entidad federativa. En el estado de Oaxaca diarios como El Imparcial y Noticias también informaron en sus páginas sobre desapariciones, entre 1978 y 1979, incluso publicaron entrevistas con aquellos que fueron liberados de la detención-desaparición. Tampoco se pueden olvidar aquellas revistas como Proceso (desde 1977), Por qué? (1968-1974) o Por Esto (1981-1990), que difundían testimonios sobre la violencia de Estado y notas sobre los crímenes cometidos por las policías y los órganos de seguridad nacional.

${ }^{20}$ Los comunicados de la ACNR se encuentran compilados en Antonio Aranda, Los civicos guerrerenses. 
Se puede decir, entonces, que ya desde los años más duros de la contrainsurgencia, la detención-desaparición ocupó un lugar en la prensa. Por lo que la categoría del "detenido-desaparecido originario" no se transnacionaliza a un territorio vacío, y tampoco desplaza la experiencia de las desapariciones de la contrainsurgencia en México. Por eso fue posible la reactivación, en la memoria, de estos casos del pasado reciente y vincularlos (de manera acrítica, cierto) con el de los 43 estudiantes normalistas desaparecidos en Iguala, Guerrero, en 2014.

\section{LA IMPOSIBILIDAD DE UN CAMPO}

En la conformación de un campo entran en juego diversos factores. Por ejemplo, la transición misma es un factor político relevante para la construcción de un campo de la desaparición y de las violencias políticas de Estado, en particular la justicia transicional, como lo mostraron los distintos juicios a juntas militares o civiles vinculados a la represión política, así como las Comisiones de la Verdad en sus distintas modalidades, que aparecieron hacia finales de la década de 1980 y durante la de 1990 en distintos países del Cono Sur y Centroamérica. ${ }^{21}$ A raíz de éstas se desencadenaron estudios, disputas y discusiones en el ámbito público, ya sea acompañando o cuestionando el trabajo de dichas comisiones, que a la larga contribuyeron en la creación de campos, en particular de la desaparición forzada. En México, la idea y el discurso de la transición política se agotó muy pronto, y quizá el primer signo de agotamiento fue la forma con la que se pretendió atender los crímenes cometidos por el Estado mexicano bajo el régimen priista entre las décadas de 1960 y 1980, a través de la

${ }^{21}$ Priscilla Hayner, Verdades innombrables. El reto de las comisiones de la verdad; y Ezequiel González-Ocantos, The Politics of Transitional Justice in Latin America: Power, Norms, and Capacity Building.

64 / Camilo Vicente Ovalle 
Fiscalía Especial para Movimientos Sociales y Políticos del Pasado (Femospp), que fue cerrada por la falta de voluntad política real, por las presiones del priismo nacional, y en medio de acusaciones de desvío de fondos. ${ }^{22}$

La influencia de factores externos, como por ejemplo los organismos internacionales, juegan también un papel fundamental. $\mathrm{Su}$ intervención en México en relación con los mecanismos de represión, en especial la desaparición forzada, implantados por el Estado fue limitada, a diferencia de otras experiencias, quizá por la política de asilo que se desarrolló en los mismos años de la represión interna. También los procesos de memoria tienen un papel relevante en la formación de estos campos, en particular algunos "motores de memoria" -como les denomina la historiadora Eugenia Allier-, ${ }^{23}$ como pueden ser las organizaciones de familiares de víctimas, que en México en muy pocas ocasiones pudieron, en medio de un régimen autoritario, colocar como demanda política el esclarecimiento de los crímenes de Estado.

Finalmente, la emergencia de una disciplina que considerara al pasado reciente como un objeto de estudio, como es el caso de la historia reciente o historia del presente. ${ }^{24}$ Esta corriente historiográfica, que tomó forma hacia finales de la década de 1950 en Francia y Alemania, en América Latina comenzó su cultivo en el periodo postautoritario, en los procesos de lucha por la demo-

\footnotetext{
${ }^{22}$ Sobre el caso de la Femospp véase Sergio Aguayo Quezada y Javier Treviño Rangel, "Fox y el pasado. La anatomía de una capitulación"; Silvia Dutrénit y Libertad Argüello, "Una gestión atrapada. El caso de la FEMospp"; y Ezequiel González-Ocantos, Shifting Legal Visions: Judicial Change and Human Rights Trials in Latin America, pp. 206-68.

${ }^{23}$ Sobre los procesos y disputas por la memoria en América Latina véase Eugenia Allier Montaño y Emilio Crenzel, Las luchas por la memoria en América Latina. Historia reciente y violencia politica.

${ }^{24}$ Sobre algunos aspectos de la historia reciente y de la historia del tiempo presente puede consultarse: Marina Franco y Florencia Levín, Historia reciente. Perspectivas y desafios para un campo en construcción; Henry Rousso, The Latest Catastrophe. History, the Present, the Contemporary; y Eugenia Allier Montaño, "Ética y política en el historiador del tiempo presente".
} 
cracia y sobre todo alrededor del tema de las graves violaciones a derechos humanos. En México, su desarrollo es tardío, hacia comienzos de la década del 2000.

Todos estos elementos juegan en la conformación de un campo de estudio sobre las violencias de Estado. Del impulso que cada uno de estos elementos tenga o de la articulación de varios de ellos ha dependido la velocidad o la fuerza con la que aparece un campo, ya sea académico o social, sobre las violencias políticas y de Estado.

Considerando el desarrollo histórico de la desaparición en México, y las debilidades explicativas de la hipótesis sobre la transnacionalización para el caso mexicano, en lo que sigue me interesa presentar algunos aspectos que jugaron en contra de la posibilidad de desarrollar de manera temprana un campo sobre el fenómeno de la detención-desaparición. En este texto se deja de lado aquellos elementos que formaron parte de la propia estrategia contrainsurgente, como el discurso público sobre el enemigo y la configuración clandestina de la práctica represiva, cuya función fue ocultar la práctica misma. ${ }^{25} \mathrm{Me}$ interesa poner a discusión algunos elementos que, no formando parte de la contrainsurgencia, por razones distintas también contribuyeron a su ocultamiento. Uno de los aspectos es de tipo teórico y otro de carácter ideológico.

\section{Autoritarismo y represión}

El primer elemento se trata de una suerte de velo epistémico que cubrió el grado de represión política y el papel que cumplió en ella la desaparición de personas.

En 1975 el politólogo Juan Linz publicó su texto Totalitarian and Authoritarian Regimes, que tuvo una influencia significativa

${ }^{25}$ Camilo Vicente Ovalle, "El enemigo que acecha. Enemigo político y represión en México en la década de 1970"; y Camilo Vicente Ovalle, "Verdad de Estado y discursos de la contrainsurgencia”. 
no sólo en los estudios politológicos sino en las ciencias sociales. En su propuesta taxonómica de los autoritarismos y totalitarismos, México formaba parte de la gran familia autoritaria, es decir, de ese amplio conjunto de regímenes no-democráticos que no observaban las características de los totalitarismos ni de las democracias occidentales. El subtipo al que, de acuerdo con Linz, pertenecía México, era el de regímenes autoritarios de movilización (mobilizational authoritarian regime). ${ }^{26}$ Además del pluralismo limitado, la otra dimensión central en la definición de los tipos autoritarios era el nivel y la forma de la movilización política. Aunque en los regímenes autoritarios se tiende a limitar la movilización y despolitizar toda acción ciudadana, en el subtipo "autoritarios de movilización" existe la participación dirigida de los ciudadanos a través de canales bien definidos y monopolizados por el Estado, y cierta movilización a través del partido único o dominante y sus organizaciones. ${ }^{27}$ Un señalamiento importante que hace Linz sobre esta dimensión es que es muy inestable o su control difícil, lo que obliga al régimen a oscilar entre los extremos del espectro: el totalitarismo o la democracia. ${ }^{28}$

En la tipología desarrollada por Linz se privilegian las estructuras institucionales del poder y sus usos, y aunque se consideran los mecanismos de represión política dentro de los usos del poder, ocupan un papel secundario y no definitorio de las tipologías. Lo mismo pasa con el terror de Estado. ${ }^{29}$ De tal manera que las formas de represión política no formaron parte del marco interpretativo,

${ }^{26}$ Juan Linz, Totalitarian and Authoritarian Regimes, pp. 176-181.

${ }^{27}$ Ibidem, pp. 176-177.

28 "Mobilization and participation ultimately become difficult to sustain unless the regime moves in a more totalitarian or democratic direction". Ibidem, p. 166. ${ }^{29}$ Sobre la construcción de su modelo y la relación con el terror, Linz señaló: "It is not based as much on the distinction between democracy and totalitarianism, which I considered to the start to be obvious, nor on Hannah Arendt's emphasis on terror". Ibidem, p. 4; también señaló: "The mechanisms of control probably differentiated totalitarian regimes as much as the more obvious horrors of repression". Ibidem, p. 25. 
al colocarlas en un punto ciego del análisis; se pone énfasis en las estructuras institucionales del poder y en ciertas dinámicas de inclusión/exclusión. Este marco analítico tuvo sus resonancias en los análisis y debates sobre el régimen político mexicano durante las décadas de 1970 y $1980 .{ }^{30}$ Por ejemplo, en el clásico texto sobre la clase política mexicana, Los laberintos del poder, Peter H. Smith señaló:

Si es cierto que el autoritarismo consiste esencialmente en un pluralismo limitado, entonces hay que determinar quiénes quedan dentro y quiénes quedan fuera de los límites del poder; quién tiene y quién no tiene el derecho funcional para organizarse y para competir por el poder, igualmente urgente sería entonces entender el comportamiento de las élites autoritarias y las "reglas" de su juego político. ${ }^{31}$

Se dejan de lado tanto los mecanismos de movilización que hacen al régimen tender hacia el totalitarismo o la democracia, ${ }^{32}$

\footnotetext{
${ }^{30}$ Es justo decir que, aunque las definiciones de Linz tuvieron un peso significativo en la ciencia política mexicana y latinoamericana, no hay que desestimar el conjunto de la discusión que se dio en torno a la naturaleza de los nuevos autoritarismos entre las décadas de 1960 y 1970, que fueron conceptualizados de las más distintas formas: dictaduras de nuevo tipo, fascistización del Estado, fascismo dependiente, régimen de seguridad nacional, Estado contrainsurgente, Estado burocrático-autoritario. Una diferencia central, es que mientras que Linz incluyó a México en una tipología, en las conceptualizaciones de los intelectuales latinoamericanos se le excluyó. Para esta discusión véase: Ruy Mauro Marini, "El Estado de contrainsurgencia"; Agustín Cueva, "La fascistización del Estado en América Latina"; Teotonio Dos Santos, "El fascismo dependiente y sus contradicciones"; Guillermo O'Donell, El Estado burocrático autoritario; Guillermo O’Donell, "Las Fuerzas Armadas y el Estado autoritario del Cono Sur de América Latina"; Luis Maira, "Las nuevas dictaduras militares en América Latina"; y David Collier, The New Authoritarianism in Latin America.

${ }^{31}$ Peter H. Smith, Los laberintos del poder. El reclutamiento de las élites politicas en México, 1900-1971, pp. 5-6.

${ }^{32}$ Cosío Villegas situó la singularidad del sistema político mexicano en haber podido mantenerse estable sin acudir a ninguno de los extremos: "La singularidad, notable en sí misma, de esta estabilidad política y de semejante progreso econó-
}

\section{8 / Camilo Vicente Ovalle}


de acuerdo con Linz, así como las dinámicas y estructuras de la represión política. Por otra parte, en su expresión histórico-política, el subtipo en el que se incluyó al régimen autoritario mexicano no usaba la represión como mecanismo principal de exclusión; de hecho, se le consideró al mexicano un autoritarismo incluyente, ${ }^{33}$ flexible ${ }^{34} \mathrm{o}$ moderado, ${ }^{35}$ por su estructura corporativa y su tendencia a la cooptación más que a la eliminación de la disidencia. Y en efecto, esta estructura y dinámica política le dieron al régimen mexicano mayor estabilidad que otras experiencias autoritarias. En este marco, parece válido preguntarse por el lugar y el papel que se les asignó o reconoció a las formas de represión política y control en el régimen autoritario mexicano en la historiografía política.

En los trabajos publicados sobre el autoritarismo y el sistema político mexicano hacia finales de los años setenta y los primeros de la década de 1980, ya se incluían algunas reflexiones sobre la represión política y su papel dentro del régimen autoritario. ${ }^{36}$ Sin embargo, se le dio un tratamiento marginal, se le consideró un pilar menor para la reproducción y legitimación del régimen autoritario, frente al corporativismo, o las prácticas de coopta-

mico crece si se reflexiona que México lo ha conseguido sin acudir a ninguna de las dos fórmulas políticas consagradas: la dictadura o la democracia occidental". Daniel Cosío Villegas, El sistema político mexicano, p. 20.

${ }^{33}$ Lorenzo Meyer, "Introducción: revolución, nacionalismo y autoritarismo", p. 10.

${ }^{34}$ José Luis Reyna y R. S. Weinert, Authoritarianism in Mexico, pp. 169-170.

${ }^{35}$ Peter H. Smith, "El imperio del PRI”, p. 330.

${ }^{36}$ En esos años la producción y publicaciones sobre el carácter de los nuevos autoritarismos y el carácter del Estado en México fue ingente, en gran medida animada por el asilo latinoamericano y, obviamente, porque casi todos los países de la región tenían un régimen autoritario, circunstancia que obligó a la reflexión. A manera de alícuota traigo a cuenta los siguientes textos que muestran un panorama sobre la discusión en esos años: Arnaldo Córdova, "Las reformas sociales y la tecnocratización del Estado mexicano"; Lorenzo Meyer, "El Estado mexicano contemporáneo"; Julio Labastida, "Proceso político y dependencia en México (1970-1976)”; y Sergio Zermeño, "De Echeverría a De la Madrid: ¿̨hacia un régimen burocrático-autoritario?”. 
ción-negociación, por ejemplo. ${ }^{37}$ En ese tratamiento marginal pueden ubicarse diversos grados o posiciones que le son reconocidas a los mecanismos de represión, que van desde aquellas que la consideran como un momento originario de la modernización del autoritarismo mexicano, que se actualiza de manera excepcional y particular: "La represión es un recurso permanente contra todo movimiento popular y obrero que lucha por fuera de la coalición gubernamental. Es el último recurso. Y también el primero. Se usa cuando han fallado todas las demás instancias, y como forma de recomponer las fuerzas y reiniciar los procesos de captación, conciliación, arbitraje". ${ }^{38} \mathrm{O}$ aquellas que consideraron que en el desarrollo histórico político del régimen autoritario éste implementó mecanismos abiertamente represivos en su consolidación, pero que a la larga los fue dejando, optando por estrategias de conciliación y cooptación, tendencia histórica que se confirmaría, según estas posiciones, durante las décadas de 1960 y 1970, de acuerdo con José Luis Reyna: "The means by which capital has been accumulated, as well as the political mechanisms to regulate demands, have varied over time. During the 1940s and part of the 1950s, the latter were based mainly on repressive measures. Since 1960, the emphasis has been on granting more and repressing less". ${ }^{39}$

${ }^{37}$ En este mismo sentido, Wil G. Pansters muestra la poca atención que los mecanismos represivos han tenido en los estudios sobre el México contemporáneo. Véase la introducción en Wil G. Pansters (ed.), Violence, Coercion, and State-Making in Twentieth-Century Mexico: The Other Half of the Centaur, pp. 26-32.

${ }^{38}$ Pablo González Casanova, "El Estado y las masas", p. 214. El historiador Lorenzo Meyer también abordó de modo similar la posición de la represión dentro del régimen autoritario: "La represión no es muy evidente pero se usa sin constreñimiento contra quienes intentan una transformación sustantiva del sistema o suplantar en el poder. Esta destrucción de toda oposición coordinada y la cooptación, ambas ejercidas con sistematicidad, así como la existencia de grupos semiautónomos evitan que el sistema evolucione hacia uno de los dos modelos clásicos". Lorenzo Meyer, "Cambio político y dependencia. México en el siglo XX", p. 24.

${ }^{39}$ Reyna y Weinert, Authoritarianism in Mexico, op. cit., p. 156.

\section{0 / Camilo Vicente Ovalle}


Por otra parte, en comparaciones que se volvieron comunes, se consideró que el autoritarismo mexicano fue de un tipo más suave, por decirlo de alguna manera, frente a los regímenes del Cono Sur, y de esta conceptualización se derivó que sus estrategias represivas, en apariencia, no pudieron ser tan agresivas y criminales. En la siguiente cita Peter H. Smith ilustra esta posición:

México ha tenido un régimen autoritario pragmático y moderado en vez del tipo celosamente represivo que apareció en el Cono Sur durante los años sesenta y setenta; un sistema inclusivo, dado a la cooptación y a la incorporación en vez de la exclusión o aniquilamiento; un sistema institucional en lugar de un instrumento personalista; y unos líderes civiles en vez de gobernantes militares.

[...]

Fuera de la estructura de partidos habia movimientos terroristas, así urbanos como rurales, a los cuales el gobierno no daba cuartel. Las medidas represivas y las campañas contras las guerrillas por parte de las unidades del ejército y la policía aplastaron sin piedad a las rebeliones armadas. El régimen encarcelaba a personas por motivos políticos, hecho que las autoridades negaban a menudo, y hubo momentos de represión total. De vez en cuando desaparecían misteriosamente activistas y agitadores. ${ }^{40}$

El uso de métodos represivos para contener o eliminar a la disidencia política, de acuerdo con este autor, no alcanzó para modificar la cualidad "moderada" del autoritarismo mexicano. Esta perspectiva sobre el régimen mexicano ha permanecido y sigue vigente en amplios círculos académicos. En un interesante libro colectivo aparecido en 2014, bajo la coordinación de los historiadores Paul Gillinham y Benjamin T. Smith, éstos elaboraron una definición teórica más sofisticada, considerando al régimen posrevolucionario como una "dictablanda":41

\footnotetext{
${ }^{40}$ Smith, "El imperio del PRI", op. cit., pp. 330-333. Cursivas mías.

${ }^{41}$ Paul Gillingham y Benjamin T. Smith, "Introduction: The paradoxes of Revolution", p. 27.
} 
As a result, even after historians unearthed significant levels of violence in Mexico, extreme coercion did not have the same "crucial importance" as in bureaucratic authoritarian regimes [...] Authoritarianism is a well-populated genus, though, and two species do describe much of mid-century Mexico's political reality: electoral authoritarianism and competitive authoritarianism. ${ }^{42}$

Entonces, a lo largo de las décadas de 1970 y 1980, teóricamente se tendió una especie de velo sobre las formas represivas específicas del autoritarismo mexicano; se le colocaron por fuera del paradigma, por decirlo de alguna manera, y por tanto fuera de lo que era posible y necesario conocer. La desaparición forzada, las torturas, los asesinatos, el encarcelamiento y el exilio de la disidencia política de esas décadas no formaron parte del análisis, y por lo tanto no hubo explicaciones sobre su papel específico dentro del régimen autoritario.

Este marco teórico, con el cual fue interpretado el régimen político mexicano, puso a un lado los mecanismos específicos de la violencia de Estado contra la disidencia política, por lo que fue un factor para no observar la técnica de la detención-desaparición y los costos sociales que esto traería.

\section{La impaciencia suicida: la izquierda y sus enemigos internos}

El segundo elemento para poder explicar la ausencia de un campo, o de estudios o análisis sobre la represión política, en particular sobre la detención-desaparición forzada, es de carácter ideológico. Hay que recordar que en el espectro académico e intelectual, ciertos sectores liberales y de la izquierda que se autodefinían como socialistas y comunistas -que podían haber iniciado reflexiones más o menos detalladas y profundas respecto de la desaparición forzada y su significación para el sistema político- se encontraban confrontados de lleno con aquellos sectores llamados de

${ }^{42}$ Ibidem, pp. 21-22. Cursivas mías.

72 / Camilo Vicente Ovalle 
ultraizquierda que estaban siendo objeto de la estrategia contrainsurgente durante la década de 1970 -el movimiento armado y organizaciones populares radicales-, a tal punto de considerarlos como funcionales al régimen si no es que abiertamente sus enemigos.

Una formulación simple, atribuida al periodista Fernando Benítez, da cuenta de las consideraciones que ciertos sectores intelectuales tenían para con el gobierno de Echeverría, colocándolo en el extremo opuesto de las dictaduras latinoamericanas: "Echeverría o el fascismo", haciendo referencia a que las acciones de los grupos radicales de izquierda podían forzar una transición a un régimen dictatorial. Al comentar las acciones del Frente Urbano Zapatista (FUz) en 1971, Carlos Fuentes abundó sobre esta valoración, sosteniendo que la represión y la dictadura serían el resultado de una estrategia ajena al propio régimen: “¿Cuáles podrían ser sus propósitos? Me parecen obvios: establecer una dictadura fascista en México. ¿Cómo? Obligando a Echeverría a reprimir; y si no lo hace, declarándolo débil e incompetente para enseguida escenificar un golpe de fuerza e instalar la dictadura”. ${ }^{43}$

Muy pronto se pasó de la crítica política del radicalismo de izquierda, a formulaciones intelectuales que pusieron a estos sectores como entes fuera del campo de lo político, grupos enloquecidos en una carrera irracional hacia la muerte, y por lo tanto enemigos que, de alguna manera, era adecuado eliminar. Octavio Paz quizá fue el más furibundo promotor de esta visión:

ahora los grupitos se están transformando en una minúscula orquesta crepuscular de ranas y grillos que toca una delirante musiquita en las afueras de la realidad. El tema de esta estridente partitura, su sonsonete, es "la revolución ahora mismo" pero su

${ }^{43}$ Carlos Fuentes, "La disyuntiva mexicana”, pp. 192-193. Esta cita es una nota añadida en octubre de 1971, comentando el secuestro del empresario y director de aeropuertos Julio Hirschfeld Almada el 27 de septiembre, por un comando del Frente Urbano Zapatista. 
verdadero significado, lo que llaman los psicoanalistas el contenido latente, es el suicidio politico. ${ }^{44}$

Un poco después, en 1973, Paz sostendrá sobre los grupos guerrilleros:

Esto último es lo que ha ocurrido recientemente en América Latina y ahora, en escala menor, en México. Los grupos guerrilleros latinoamericanos, generalmente compuestos por jóvenes de la clase media, han fracasado porque no son representativos de las aspiraciones populares. Más que una disidencia revolucionaria son una excepción nihilista. Oscilan entre Viriato y Fantomas. Son una nostalgia y una impaciencia que se resuelven en un charco de sangre. ${ }^{45}$

La caracterización de los grupos radicalizados, sobre todo los guerrilleros, como "suicidas", fue rápidamente integrada a la estrategia contrainsurgente como parte de la construcción del enemigo. Esta caracterización del enemigo permitió la aplicación de tácticas de aniquilamiento, como la desaparición forzada en ciertos momentos, presentadas al público como deseo de muerte de la propia víctima. ${ }^{46}$ Es interesante señalar esta "afinidad" entre los discursos de los intelectuales liberales como Fuentes y Paz, y el discurso que formó parte de ciertas estrategias de represión política o de aniquilamiento. No es una observación sólo retórica, pues estos discursos colocaron a aquellos sobre quienes se desencadenó la represión más agresiva no nada más como los propios causantes de su desgracia, sino como el verdadero objetivo oculto de sus tácticas políticas.

${ }^{44}$ Octavio Paz, "Burocracias celestes y terrestres", p. 110. Carta de Paz a Adolfo Gilly, preso en Lecumberri, originalmente publicada en la revista Plural en febrero 1972. Cursivas mías.

${ }^{45}$ Octavio Paz, "Entre Viriato y Fantomas". Primero publicada en la revista Plural en junio de 1973.

${ }^{46}$ Camilo Vicente Ovalle, "El enemigo que acecha. Enemigo político y represión en México en la década de 1970 ”.

74 / Camilo Vicente Ovalle 
Esta confrontación ideológica, que en algunos casos llegó al enfrentamiento físico entre los sectores de la izquierda -la radical y la reformista (como se les conoció a aquellos sectores que consideraron la apertura política ofrecida por Luis Echeverría y López Portillo)-, alcanzó los espacios académicos. Durante las décadas de 1970 y 1980 el argumento netamente ideológico puso otro velo sobre la represión política de esos años: además de impedir la observación y cuestionamiento de la represión sobre ciertos grupos, en algunos casos la validó. Octavio Paz, refiriéndose al sector de la Federación de Estudiantes de Sinaloa, conocidos como "Los enfermos", que se integró a la Liga Comunista 23 de Septiembre (LC23s), señaló: "Los 'Enfermos', como se llamaba a sí mismo uno de estos grupos (el de la Universidad de Sinaloa), se han vuelto los Incurables." ${ }^{47}$ ¿Qué se hace con lo incurable? Hacia mediados de la década de 1970 ya se había configurado la eliminación de estos grupos como la estrategia necesaria y deseable.

En expresiones académicas más refinadas, también aparecieron este tipo de interpretaciones. Por ejemplo, en su historia sobre el Partido Comunista Mexicano (РСM), Barry Carr hizo el siguiente señalamiento sobre la confrontación entre sectores de izquierda en Culiacán, muy cercano a lo expresado por Paz:

En Culiacán, en 1973-1974, los atinadamente llamados Enfermos, un grupo ultraizquierdista con fuerte regusto a militarista y terrorista, obtuvieron el control temporal de secciones de la Federación de Estudiantes Universitarios de Sinaloa, en particular las de alumnos de preparatorias y los que vivían en casa de estudiantes. Los Enfermos se lanzaron violentamente contra los estudiantes de izquierda y los miembros del Partido Comunista que habían obtenido el control parcial de la administración a principios de $1973 .^{48}$

\footnotetext{
${ }^{47}$ Octavio Paz, "El plagio, la plaga y la llaga”, p. 161. Publicado en Plural en septiembre de 1974. Cursivas mías

${ }^{48}$ Barry Carr, La izquierda mexicana a través del siglo XX, p. 273. Cursivas mías
} 
En muchos casos, militantes de izquierdas durante las décadas de 1970 y 1980, confrontados con los sectores radicales o con el movimiento armado, después accedieron, o ya se encontraban, en espacios dentro de instituciones académicas, y delinearon desde allí la interpretación sobre la historia reciente y la violencia política, con el velo ideológico que acarrearon del periodo de confrontación. ${ }^{49}$

En un trabajo temprano, al calor de los hechos, en el que se presentan análisis sobre el conflicto político y social en el estado de Oaxaca, un grupo de académicos, varios de los cuales habían militado en organizaciones confrontadas con el movimiento radical encabezado por el Movimiento Democrático Universitario y los grupos armados, en particular la Unión del Pueblo, presentaron balances teóricos y políticos sobre la experiencia de movilización entre 1968 y 1977, en los cuales se filtró ese velo ideológico. Sobre los activistas estudiantiles que decidieron vincularse al movimiento armado, por ejemplo, se dice:

Aquellos otros que no saldrán de las escuelas, pero que se "adhieren" de palabra a las acciones militaristas, hacen del activismo su "modus vivendi", cayendo en un proceso de descomposición acelerada que llevará a algunos al bando contrario, otros más se retirarán a sus casas. Esta “enfermedad" que hizo presa sobre todo a los preparatorianos ("los comitecos"), causará algunos problemas a la COCEO en su quehacer político. ${ }^{50}$

${ }^{49} \mathrm{El}$ debate político sobre el uso de la violencia y su validez histórico-política alcanzó momentos interesantes en la academia de izquierda mexicana, pero siempre concluía con el abierto rechazo y marginación de lo que se consideraba tan sólo como una mera violencia aventurera. Véase, por ejemplo, Carlos Pereyra Boldrini, "Política y Violencia".

${ }^{50}$ Francisco Ruiz Cervantes, "La lucha de clases en Oaxaca: 1971-1977 (segunda parte)”, p. 55. Cursivas mías. En otro de los ensayos, Miguel Lozano señala con mayor contundencia: "Si se analiza la composición de los grupos que lanzaron el señalamiento ya mencionado, se observa que lo integran en forma dominante, elementos de condición pequeñoburguesa, la mayoría de ellos extraídos de los medios estudiantiles. [...] A esto se debe lo incorrecto de sus planteamientos como lo inconsistente de su actuación. Al mismo tiempo significa que no han

\section{6 / Camilo Vicente Ovalle}


En otro de los textos clásicos sobre la historia política oaxaqueña reciente, de Víctor Raúl Martínez Vázquez, Movimiento popular y politica en Oaxaca (1968-1986), el autor ofrece una cronología comentada muy interesante, y aporta algunos datos importantes en torno al periodo 1970-1980, así como un análisis sobre la composición orgánica del poder en el estado. Sin embargo, es evidente que está escrito desde una posición política contraria a los grupos armados y a los grupos cercanos a Felipe Martínez Soriano. Hay que recordar que Víctor Raúl fue cercano a la Coalición Obrera Campesina Estudiantil de Oaxaca (coceo) y formó parte de la Comisión Coordinadora que intentó servir de transición del gobierno universitario en 1977, confrontada con el sector encabezado por Martínez Soriano. Tal es así, que desdeña por completo la actuación de éstos, salvo cuando son presentados como corresponsables de la represión, del fracaso de la movilización popular y de haber actuado como grupos de choque contra los grupos "democráticos".

Objetivamente, los actos de la guerrilla urbana repercutían contra el movimiento de masas y del cual estaban totalmente desligados; tales hechos alimentaban el clima anticomunista que marcó el ambiente político de Oaxaca durante el régimen de Zárate Aquino. Sin pretenderlo quizás, las acciones de la Liga 23 de Septiembre y de la Unión del Pueblo eran aprovechadas por la burguesía y el gobierno contra el movimiento popular, transformándose en la práctica en instrumentos de confusión..$^{51}$

tenido influencia ni trascendencia entre los trabajadores para extraer de ahí, a la mayoría de sus cuadros [...] De ahí que este grupo de gentes cada vez actúe con un terrorismo suicida, alejándose también cada vez más de las masas trabajadoras; y al carecer de influencia en ellas, se aniquila por su parte a gentes que pertenecen a los grupos democráticos, pensando encontrar en estos grupos sus errores, y su falta de influencia sobre el proletariado". Miguel Lozano, "Oaxaca: una experiencia de lucha”, pp. 192-193.

${ }^{51}$ Víctor Raúl Martínez Vázquez, Movimiento popular y política en Oaxaca 19681986, p. 172. 
Por otra parte, el ejercicio represivo del gobierno del estado y las dependencias federales apenas es dibujado. Al parecer, para el autor, la estrategia privilegiada fue la contención y la negociación. Nada se dice de los asesinatos y desapariciones contra militantes de la LC23s, ni contra los militantes de la Unión del Pueblo. Hay que señalar que en el caso de Oaxaca esta confrontación entre las dos posiciones de la izquierda alcanzó los más altos niveles. El punto de quiebre fue la ejecución del militante del Partido Comunista Mexicano (РСM) en Oaxaca, Carlos Hernández Chavarría, por un comando de la Unión del Pueblo el 22 de febrero de 1978. Esta ejecución fue cuestionada de manera abierta, y significó el aislamiento y la desconfianza generalizada contra el grupo guerrillero. Todas aquellas sospechas de que era un grupo infiltrado por la policía, parecían confirmarse con la ejecución de Hernández Chavarría. En un comunicado, la Unión del Pueblo explicó su acción:

En Oaxaca, durante el movimiento popular universitario, se llevó la actitud honesta y combativa, obedeciendo al lineamiento de guerra popular de nuestra organización, que de brazo con el pueblo, desenmascaró al Estado Burgués y al oportunismo ganando la calle y enfrentándose contra la policía, construyendo la conciencia revolucionaria Marxista Leninista de las masas, rebasando la lucha académica y económica generando la lucha política de masas, fue entonces que el gobierno local burgués es derrotado y busca nuevos aliados, los encuentra y los incrusta dentro del movimiento. Nos referimos a sus hijos adoptivos, Partidos supuestamente de Izquierda, de camarillas desequilibradas, con máscaras de Marxistas como el Partido Comunista Mexicano, M.E.R., P.R.T. (Trotskistas) repudiados, expulsados $\mathrm{y}$ ajusticiados de todas las revoluciones socialistas Marxistas-Leninistas, éstos (P.C.M.) se infiltran en el movimiento e intentan mediatizar y conducir a las masas por el camino de la conciliación de las clases, pero las masas las repudian y los desenmascaran y al sentirse repudiados se unen al fascista y sanguinario P.R.I. [...] El 
camino de Chavarría como el de los oportunistas era y es el hacer Currículo Vitae y aprovechando la supuesta falta de politización de las masas, fanfarroneando su lenguaje "MARXISTA", vivir como un burgués vendiéndose al Estado, jalando a uno que otro vacilante a los caminos de la contrarrevolución... ${ }^{52}$

En el caso del estado de Sinaloa hubo un proceder similar. Exmilitantes, que después se convirtieron en académicos e intelectuales, conservaron sus disputas ideológicas, tendiendo el velo sobre las políticas represivas. Exlíderes del movimiento estudiantil, como Liberato Terán, o intelectuales como Carlos Calderón Viedas, son representativos de estas posiciones. En el prólogo a un libro en el que participan Terán y Viedas, Gilberto Guevara Niebla, primo del estudiante Carlos Guevara, asesinado en un choque con "Los Enfermos" en 1973, hace el siguiente balance sobre este grupo, que da una idea clara de la posición general de los textos del libro:

Los Enfermos no representan, desde luego, ninguna formación política de izquierda. Se trata más bien de una experiencia de terrorismo estudiantil que tuvo como consecuencias trágicas, delirantes y sobrecogedoras para la UAS y para el estado de Sinaloa. La locura de este grupo sólo es comparable a la exaltación de la violencia por la violencia que hicieron, en su momento, los "camisas pardas" nazis en Alemania o los "camisas negras", vástagos de Mussolini en Italia. ${ }^{53}$

Además, en el caso de Sinaloa es claro que no se quedó en exclusiva en una posición intelectual, sino que asumió un nivel dentro de la práctica política, particularmente en los momentos

\footnotetext{
${ }^{52}$ Archivo General de la Nación, fondo Dirección Federal de Seguridad, "Comunicado guerrillero", 28 de febrero, 1978, en expediente Unión del Pueblo versión pública, legajo 11/18, 2009.

${ }^{53}$ Gilberto Guevara Niebla, "Prólogo", p. 14.
} 
iniciales de la lucha por la amnistía política y la exigencia de presentación de los desaparecidos en el estado, entre finales de la década de 1970 y los primeros años de la de 1980. En una entrevista con un exmilitante del Partido Comunista y del grupo estudiantil Los Chemones, confrontado con Los Enfermos, ante la pregunta de por qué ese sector de la izquierda sinaloense, al que él perteneció, no se involucró en la exigencia de la presentación de los desaparecidos, respondió:

Sí nos involucramos, no con el fervor de ellos [exmilitantes de la Liga o familiares de las víctimas], no con ese fervor, porque hubo enfrentamientos personales también, porque de una u otra manera los compañeros nuestros que cayeron ellos los mataron, entonces había esa parte, a Carlos Guevara lo matan ellos, lo matan gente del grupo de Los Enfermos, a Heberto lo van a agredir gente ligada a los Enfermos [...] Nosotros no nos adueñamos aquí en Sinaloa del movimiento que encabezó doña Chuyita Barrón, ni tampoco hicimos nuestra al cien por ciento la lucha de dońa Rosario Ibarra de Piedra [...] Nosotros nos vamos a meter, el Partido Comunista va a salir de la clandestinidad aquí en Sinaloa, va a participar en la primera elección en el 79, nosotros estamos en la construcción de un partido de masas... y no hicimos el eje fundamental de nuestra existencia de lucha la presentación de los desaparecidos, quizá porque nosotros teníamos menos desparecidos en nuestras filas, quizá porque fuimos víctimas de esa política equivocada de ellos, pero de que nos solidarizábamos sí lo hacíamos, pero el centro de nuestra existencia política no fue esa... ${ }^{54}$

El velo ideológico que cubrió a ciertos sectores de la izquierda académica e intelectual fue un factor determinante en la ausencia de estudios sobre las formas específicas de la represión política en México, en particular sobre la detención-desaparición forzada

${ }^{54}$ Entrevista JRR/CUL/2014-1, 18 de octubre, 2014, Culiacán, Sinaloa.

80 / Camilo Vicente Ovalle 
durante las décadas de 1970 y 1980 . Y, al final, se convirtió en un factor que no permitió o no facilitó la emergencia de un campo, ni en el ámbito académico ni en el político, en torno a las desapariciones forzadas de la contrainsurgencia, a pesar de los reclamos que por todo el país ya se escuchaban.

\section{LA NECESARIA INSCRIPCIÓN}

El reclamo “¿Dónde están?”, de madres y familiares, no siempre ha sido escuchado, ni ellas tampoco han sido siempre acompañadas en sus búsquedas de justicia y de sus familiares detenidos-desaparecidos. Y como he tratado de mostrar, la emergencia de un campo social, académico y político, donde cobrara realidad social un fenómeno como la desaparición, no se explica con facilidad: ni por la mera transnacionalización de una categoría a territorios supuestamente vacíos, ni tampoco por el señalamiento fácil de indiferencia o indolencia frente al desasosiego.

De los elementos presentados, es claro que la ausencia o emergencia de un campo en torno a un fenómeno como la desaparición de personas no se explica por la magnitud, y que la catástrofe social no se mide en números sino por lo que desestructura, y que el discurso del derechohumanismo no alcanza para hacer emerger un campo. La emergencia de un campo está determinada, entre otros factores, por condiciones epistémicas y políticas, que los fenómenos de violencia y de graves violaciones a derechos humanos se presentan también en las disputas políticas, y que de las fuerzas en ellas presentes depende la articulación o no del campo. Por ello, también resulta fundamental volver a pensar la figura de la víctima, que se presenta en el ámbito político como parte del capital en disputa, y su necesaria transformación en un actor sociopolítico.

La reflexión y recuperación de las experiencias de disputas en torno a la desaparición forzada entre los años de las décadas de 
1970 y 1980 resulta fundamental, no sólo para la reflexión académica, sino porque la comprensión y explicación del fenómeno de la desaparición, su desarrollo histórico y sus características presentes, pueden apoyar en la elaboración de estrategias de búsqueda y localización de personas, así como desarticular los circuitos de este crimen. Pero, por otro lado, impedirá que experiencias históricas, que han quedado inscritas en las memorias de diversas comunidades, sean desplazadas de nueva cuenta porque han perdido relevancia frente a la catástrofe presente. Y establecerá un marco en el que se pueda analizar cómo actores históricos son integrados al nuevo campo y qué sucede en ello, por ejemplo, con la categoría de víctima que se superpone a subjetividades previas. Nos encontramos ante un nuevo ciclo de violencia en el que el Estado sigue siendo central, pero ya no como principal ejecutor, sino como parte de un espacio donde se gesta una nueva estructura de gubernamentalidad, con su lógica de violencia específica y con nuevas formas de la desaparición, que exigen repensar el concepto de desaparición forzada. Por ello, resulta fundamental establecer algunas coordenadas, que no pretendan representar figuras jurídicas-penales (tipos ideales), sino que describan y presenten las complejidades de un fenómeno tal como se expresa históricamente y se despliega en el presente, para que a partir de ello se establezcan ciertas condiciones para la rearticulación histórica del concepto de desaparición forzada. 底

\section{BiBLIOGRAFÍA}

Aguayo Quezada, Sergio y Javier Trevińo Rangel. "Fox y el pasado. La anatomía de una capitulación”, Foro Internacional 47, núm. 4 (190) (2007), pp. 709-739.

Allier Montaño, Eugenia. "Ética y política en el historiador del tiempo presente", en Alfonso Mendiola y Luis Vergara (eds.), Cátedra Edmundo O 'Gorman. Teoría de la Historia, vol. 1, México, Universidad Iberoamericana/Universidad Nacional Autónoma de México, 2011, pp. 151-171.

82 / Camilo Vicente Ovalle 
Allier Montaño, Eugenia y Emilio Crenzel (eds.). Las luchas por la memoria en América Latina. Historia reciente y violencia politica, México, Bonilla Artigas Editores/Universidad Nacional Autónoma de México, 2015.

Anaya-Muñoz, Alejandro y Barbara Frey (eds.). Mexico's Human Rights Crisis, Pennsylvania Studies in Human Rights, University of Pennsylvania Press, 2019.

Anstett, Élisabeth. "Comparación no es razón: a propósito de la exportación de las nociones de desaparición forzada y detenidos-desaparecidos”, en Desapariciones. Usos locales, circulaciones globales, Bogotá, Universidad de los Andes/Siglo del Hombre Editores, 2017, pp. 33-51.

Aranda, Antonio. Los cívicos guerrerenses, México, Edición de Autor, 1979.

Bloch, Marc. Apología para la historia o el oficio del historiador, 2 a ed., México, Fondo de Cultura Económica, 2001.

Bourdieu, Pierre. Razones prácticas: sobre la teoría de la acción, tr. Thomas Kauf, , Barcelona, Anagrama, 2002 (Argumentos).

Calveiro, Pilar. Resistir al neoliberalismo: comunidades y autonomias, México, Siglo XXI Editores, 2019.

Carr, Barry. La izquierda mexicana a través del siglo XX, 4a ed., México, Era, 1996.

Collier, David. The New Authoritarianism in Latin America, New Jersey, Princeton University Press, 1979.

Comisión Nacional de Búsqueda. "Informe sobre fosas clandestinas y registro nacional de personas desaparecidas o no localizadas", México, Comisión Nacional de Búsqueda, el 6 de enero de 2020 . Disponible en: <CNB_6_enero_2020_conferencia_prensa.pdf.pdf. https://www.gob.mx/cms/uploads/attachment/file/535387/CNB_6_ener o_2020_conferencia_prensa.pdf.pdf>.

Córdova, Arnaldo. "Las reformas sociales y la tecnocratización del Estado mexicano”, Revista Mexicana de Ciencia Politica 70 (1972), pp. 61-92.

Cosío Villegas, Daniel. El sistema político mexicano, 4a ed., México, Joaquín Mortiz, 1973 (1972).

Cueva, Agustín. "La fascistización del Estado en América Latina”, en Ruy Mauro Marini y Margara Millán (eds.), La centralidad del marxismo, vol. 3, La teoría social latinoamericana, México, Universidad Nacional Autónoma de México,1995, pp. 79-87.Dos Santos, Theotonio. "El fascismo dependiente y sus contradicciones", en La centralidad del marxismo, editado por Ruy Mauro Marini y Margara Millán, vol. 3, La teoría social latinoamericana, México, 1995, pp. 101-107. 
Dutrénit, Silvia. El Uruguay del exilio: gente, circunstancias, escenarios, Montevideo, Trilce, 2006.

Dutrénit, Silvia y Libertad Argüello. "Una gestión atrapada. El caso de la FEMOSPP”, en Fernando Castañeda, Angélica Cuellar y Edith Kuri (eds.), La crisis de las instituciones politicas en México, México, Universidad Nacional Autónoma de México, 2011, pp. 111-144.

Dutrénit, Silvia y Fernando Serrano Migallón. El Exilio uruguayo en México, México, Universidad Nacional Autónoma de México/Editorial Porrúa, 2008.

Franco, Marina y Florencia Levín (eds.). Historia reciente. Perspectivas y desafios para un campo en construcción, Buenos Aires, Paidós, 2007.

Fuentes, Carlos. "La disyuntiva mexicana", en Tiempo mexicano, México, Joaquín Mortiz, 1971, pp. 150-194.

Gatti, Gabriel. "De un continente al otro: el desaparecido transnacional, la cultura humanitaria y las víctimas totales en tiempos de guerra global", Politica y Sociedad 48, núm. 3, nov. 2011, pp. 519-536. <https://doi. org/10.5209/rev_POSO.2011.v48.n3.36419>.

- El detenido-desaparecido: narrativas posibles para una catástrofe de la identidad, Montevideo, Trilce, 2008.

- "Prolegómenos. Para un concepto científico de desaparición", en Gabriel Gatti (ed.), Desapariciones: Usos locales, circulaciones globales, Colombia, Universidad de los Andes-Siglo del Hombre Editores, 2017 (Temas para el diálogo y el debate), pp. 13-32.

Gatti, Gabriel e Ignacio Irazuzta. "Diario de la desaparición mexicana. Entre el precedente y el exceso", Disparidades. Revista de Antropología 74, núm. 2, pp. 1-14, julio-diciembre 2019. <https://doi.org/10.3989/ dra.2019.02.019>.

Gillingham, Paul y Benjamin T. Smith. "Introduction: The Paradoxes of Revolution”, en Paul Gillingham y Benjamin T. Smith (eds.), Dictablanda. Politics, Work, and Culture in Mexico, 1938-1968, Durham and London, Duke University Press, 2014, pp. 1-43.

González Casanova, Pablo. "El Estado y las masas", en El Estado y los partidos politicos en México: ensayos, 3a ed., México, Era, 1986, pp. 177-201.

González-Ocantos, Ezequiel. Shifting Legal Visions: Judicial Change and Human Rights Trials in Latin America, Cambridge University Press, 2016 (Cambridge Studies in Law and Society, Cambridge(.

- The Politics of Transitional Justice in Latin America: Power, Norms, and Capacity Building, Cambridge, Cambridge University Press, 2020 (Elements in Politics and Society in Latin America).

84 / Camilo Vicente Ovalle 
Guevara Niebla, Gilberto. "Prólogo", en Carlos CalderónViedas, Jorge Medina Viedas, y Liberato Terán, La utopía corrompida. Radicalismo y reforma en la Universidad Autónoma de Sinaloa, México, Océano, 2009, pp. 13-16.

Hayner, Priscilla. Verdades innombrables. El reto de las comisiones de la verdad, México, Fondo de Cultura Económica, 2008.

Kovras, Iosif. Grassroots Activism and the Evolution of Transitional Justice. The Families of the Disappeared, Cambridge, Cambridge University Press, 2017.

Labastida, Julio. "Proceso político y dependencia en México (1970-1976)", Revista Mexicana de Sociología 39, núm. 1 (1977), pp. 193-227. <https: //doi.org/10.2307/3539795>.

Linz, Juan. Totalitarian and Authoritarian Regimes, London, Lynne Reinner Publishers, 2000.

Lozano, Miguel. "Oaxaca: una experiencia de lucha”, en René Bustamante, Cuauhtémoc González Pacheco, Francisco José Ruiz Cervantes, Miguel Lozano, Silvia Millán Echegaray y Francisco Gomezjara (eds.), Oaxaca, una lucha reciente: 1960-1983, 2a ed., México, Ediciones Nueva Sociología, 1984, pp. 75-224.

Maira, Luis. "Las nuevas dictaduras militares en América Latina", en Ruy Mauro Marini y Margara Millán (eds.), La centralidad del marxismo, vol. 3 de La teoría social latinoamericana, México, Universidad Nacional Autónoma de México, 1995, pp. 123-134.

Marini, Ruy Mauro. "El Estado de contrainsurgencia”, en Ruy Mauro Marini y Margara Millán (eds.), La centralidaddel marxismo, vol. 3 de La teoría social latinoamericana, México, Universidad Nacional Autónoma de México, 1995, pp. 89-99.

Martínez Vázquez, Víctor Raúl. Movimiento popular y politica en Oaxaca 1968-1986, México, Consejo Nacional para la Cultura y las Artes, 1990.

Meyer, Lorenzo. "Cambio político y dependencia. México en el siglo XX", en México para los mexicanos. La revolución y sus adversarios, México, El Colegio de México, 2010, pp. 15-60.

_. "El Estado mexicano contemporáneo", Historia Mexicana 23, núm. 4, abril- junio 1974, pp. 722-752.

—. "Introducción: revolución, nacionalismo y autoritarismo", en México para los mexicanos. La revolución y sus adversarios, México, El Colegio de México, 2010, pp. 9-13.

O’Donell, Guillermo. El Estado burocrático autoritario, Buenos Aires, Prometeo Libros, 2009. 
"Las fuerzas armadas y el Estado autoritario del Cono Sur de América Latina", en Norbert Lechner (ed.), Estado y política en América Latina, 7a ed., México, Siglo XXI editores, 2000, 199-234.

Pansters, Wil G. (ed.). Violence, Coercion, and State-Making in TwentiethCentury Mexico: The Other Half of the Centaur, Stanford, Stanford University Press, 2012.

Paz, Octavio. "Burocracias celestes y terrestres", en El ogro filantrópico. Historia y politica 1971-1978, 2a ed., México, Joaquín Mortiz, 1979, pp. 108-125.

."El plagio, la plaga y la llaga”, en El ogro filantrópico. Historia y política 1971-1978, 2a ed., México, Joaquín Mortiz, 1979, pp. 160-165.

—. "Entre Viriato y Fantomas", en El ogro filantrópico. Historia y política 1971-1978, 2a ed., México, Joaquín Mortiz, 1979, pp. 151-158.

Pereyra Boldrini, Carlos. "Política y violencia", en Filosofia, historia y politica: ensayos filosóficos (1974-1988), México, Fondo de Cultura Económica, 2010 (1974), (Filosofía Series), pp. 25-63.

Reyna, José Luis y R. S. Weinert. Authoritarianism in Mexico, Philadelphia, Institute for the Study of Human Issues, 1977 (Inter-American politics series).

Robledo Silvestre, Carolina. "Genealogía e historia no resuelta de la desaparición forzada en México", Íconos - Revista de Ciencias Sociales, núm. 55, 2016, pp. 93-114. বhttps://doi.org/10.17141/iconos.55.2016.1854>.

Robledo Silvestre, Carolina y May-ek Querales-Mendoza. "Presentación del dossier. Desaparición de personas en el mundo globalizado: desafíos desde América Latina”, Íconos - Revista de Ciencias Sociales, núm. 67, mayo-agosto 2020, pp. 7-15.

Rousso, Henry. The Latest Catastrophe. History, the Present, the Contemporary, tr. Jean Marie Todd, Chicago/London, The University of Chicago Press, 2016.

Ruiz Cervantes, Francisco José. "La lucha de clases en Oaxaca: 1971-1977 (segunda parte)”, en René Bustamante, Cuauhtémoc González Pacheco, Francisco José Ruiz Cervantes, Miguel Lozano, Silvia Millán Echegaray y Francisco Gomezjara (eds.), Oaxaca, una lucha reciente: 1960-1983, 2a ed., México, Ediciones Nueva Sociología, 1984 (1978), pp. 47-73.

Sferrazza-Taibi, Pietro. "Desapariciones forzadas por actores no estatales: la jurisprudencia de la Corte Interamericana de Derechos Humanos", Íconos - Revista de Ciencias Sociales, núm. 67, pp. 17-37, mayo-agosto 2020. <https://doi.org/10.17141/iconos.67.2020.4171>.

\section{6 / Camilo Vicente Ovalle}


Smith, Peter H. "El imperio del PRI", en Timothy Anna, Jan Bazant, Friedrich Katz, John Womack Jr., Jean Meyer, Alan Knight y Peter H Smith (eds.), Historia de México, España, Crítica, 2001 (1985, en inglés), pp. 321-384.

- Los laberintos del poder. El reclutamiento de las élites políticas en México, 1900-1971, México, El Colegio de México, 1981 (1979, en inglés).

Vicente Ovalle, Camilo. "El enemigo que acecha. Enemigo político y represión en México en la década de 1970”, en IgorGoicovic, Julio Pinto, Ivette Lozoya y Claudio Pérez (eds.), Escrita con sangre. Historia de la violencia en América Latina, siglos XIX y XX, Santiago de Chile, Ceibo Ediciones/Universidad de Santiago de Chile, 2013, pp. 217-242.

- [Tiempo Suspendido] Una historia de la desaparición forzada en México, 1940-1980, México, Bonilla Artigas Editores, 2019.

—_. "Verdad de Estado y discursos de la contrainsurgencia". Con- temporánea, Primera época, vol. 4, núm. 8, julio-diciembre de 2017. Disponible en: $<$ https://revistas.inah.gob.mx/index.php/contemporanea/article/ view/118 13>.

Yankelevich, Pablo. Ráfagas de un exilio: argentinos en México, 1974-1983, Argentina, Fondo de Cultura Económica, 2010.

Zermeño, Sergio. "De Echeverría a De la Madrid: ¿̨hacia un régimen burocrático-autoritario?”, Revista Mexicana de Sociología 45, núm. 2, 1983, pp. 473-506. <https://doi.org/10.2307/3540258>. 